\title{
Correction to: Role of complement and potential of complement inhibitors in myasthenia gravis and neuromyelitis optica spectrum disorders: a brief review
}

\author{
Jayne L. Chamberlain ${ }^{1}$ D . Saif Huda ${ }^{2}$. Daniel H. Whittam • Marcelo Matiello ${ }^{3} \cdot$ B. Paul Morgan ${ }^{4} \cdot$ Anu Jacob $^{2,5}$
}

Published online: 15 November 2021

() The Author(s), under exclusive licence to Springer-Verlag GmbH Germany 2021

Correction to: Journal of Neurology (2021) 268:1643-1664 https://doi.org/10.1007/s00415-019-09498-4

The original version of this article unfortunately contained a mistake. Affiliation details for Jayne L. Chamberlain were incorrectly given as "Ipsen Biopharm Ltd, 9 Ash Rd N, Wrexham LL13 9UF, UK" but should have been Ruthin, UK, e-mail: drjlc1000@gmail.com

The original article can be found online at https://doi.org/10.1007/ s00415-019-09498-4.

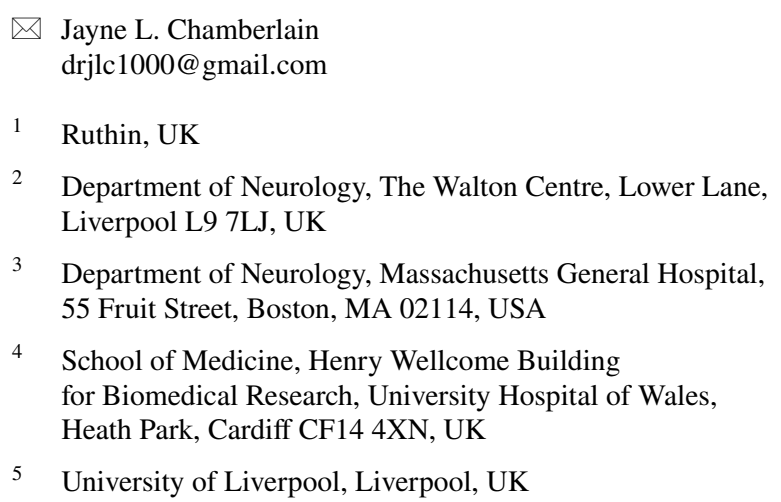

3 Department of Neurology, Massachusetts General Hospital, 55 Fruit Street, Boston, MA 02114, USA

4 School of Medicine, Henry Wellcome Building for Biomedical Research, University Hospital of Wales, Heath Park, Cardiff CF14 4XN, UK

5 University of Liverpool, Liverpool, UK 